\title{
NÃO PODEIS SERVIR A DEUS \\ E AO DINHEIRO! \\ (MT 6,24)
}

Pe. José Pedro Teixeira de Jesus e Pe. Cézar Teixeira*

\section{RESUMO}

Servir a Deus é garantir que todos possam ser respeitados em suas necessidades básicas por meio do seu próprio trabalho. Servir ao dinheiro é considerar a especulação e a exploração como mais importantes do que as pessoas. É fundamental ter clareza sobre a quem se deve beneficiar: a Deus, servindo os seus filhos, ou ao dinheiro. No entanto, não podemos pensar apenas na vida das pessoas sem proteger a economia, caso contrário, corremos o risco de empobrecimento, pois o pão de cada dia é: trabalho, economia, técnica, tecnologia, isto é, aquilo que progride. Mesmo diante de tal clareza, a realidade continua nos questionando: confiamos ou não na providência divina? Por que privar um projeto econômico do dado da fé? Será que Deus não sabe bem o que fala? Será que realmente a economia é absoluta? O ser humano não deve prevalecer acima da economia?

Palavras Chaves: dinheiro, economia, trabalho, Deus, servir.

\begin{abstract}
To serve God is ensuring that everyone can be met in their basic needs by means of the their own work. Serving to money is consider the speculation and the exploration as more important than the people. It is essential to have clarity on the to whom it should benefit: the God serving their children or to money. However, can not think only in people's lives without protecting the economy, otherwise we run the risk of impoverishment, because the daily bread is: work, economy, technical, technology, that is, what progresses. Even with such clarity the reality still us questioning. Trust we or not in the providence of God? Why deprive a project's economic data from the faith? Does God not knows good what to say? Does economy is really absolute? The human being must not prevail over the economy?
\end{abstract}

Key-words: money, economy, work, God, to serve.

\footnotetext{
* Pe. José Pedro Teixeira de Jesus e Pe. Cézar Teixeira são professores da Pontifícia Faculdade de Teologia - PUC-SP na área de Sagrada Escritura. Ambos foram formados pela Pontifícia Universidade Santo Tomás de Aquino em Roma.
} 


\section{INTRODUÇÃO}

A Campanha da fraternidade de 2010 tem como objetivo geral "colaborar na promoção de uma economia a serviço da vida, fundamentada no ideal da cultura da paz, a partir do esforço conjunto das Igrejas Cristãs e de pessoas de boa vontade, para que todos contribuam na construção do bem comum ${ }^{1}$ em vista de uma sociedade sem exclusão". ${ }^{2} \mathrm{O}$ tema desta campanha é "Economia e Vida" e o lema "Vocês não podem servir a Deus e ao Dinheiro" (Mt 6,24).

O objetivo deste artigo é colaborar para um melhor aprofundamento desse texto, provocando um debate sobre a tensão existente entre a economia de vida e a economia de morte. Como afirma o papa Bento XVI:

Cada sociedade elabora um sistema próprio de justiça. A caridade supera a justiça, porque amar é dar, oferecer ao outro do que é "meu"; mas nunca existe sem a justiça, que induz a dar ao outro o que é "dele", o que lhe pertence em razão do seu ser e do seu agir. ${ }^{3}$

Os economistas insistem na tese de que a economia é uma ciência dentro da área das humanas, porém o que se verifica muitas vezes é uma política econômica que leva em conta vários fatores, menos o fator humano e a vida.

Apontaremos alguns questionamentos advindos da Palavra de Deus, de Jesus Cristo, o Verbo de Deus encarnado (Lc 24,27; Jo 5,39). Cremos que a prática de Jesus poderá iluminar a nossa realidade econômica, apresentando um caminho que realmente leve em conta o ser humano e não o lucro.

O caminho percorrido por nós parte do texto, do contexto literário em que esse versículo está inserido, da realidade no tempo de Jesus e da tradição literária existente no Antigo e no Novo Testamento. Todo esse percurso realizado possibilitará detectar quais são os dois senhores a que o texto se refere para que possamos vislumbrar, hoje, mudanças históricas efetivas que coloquem a humanidade no caminho da fraternidade e da participação, apesar das contínuas atrocidades e das vidas sacrificadas com amor. O homem econômico, esquecido da sua verdadeira condição ontológica da partilha, continua a existir segundo sua lógica destruidora e seus deuses: os bens, o dinheiro etc. São figuras do nada pelas quais ele se deixou escravizar,

1 Cf. BENTO XVI. Caritas in Veritate. Brasília: CNBB, 2009. p. 10. § 7. Documento Pontifício 3.

2 CONIC - Conselho Nacional de Igrejas Cristãs do Brasil. Campanha da Fraternidade Ecumênica 2010. Economia e Vida. Texto-Base. Brasília: CNBB, 2009. p. 17. § 16.

3 Cf. BENTO XVI, Caritas in Veritate, p. 9. § 6. 
mas que na pluralidade das crenças e das culturas seguem aprendendo a se tornar irmãos uns dos outros e entreabrir a salvação. ${ }^{4}$

\section{O TEXTO GREGO, TRADUÇÃO, INSERÇÃO E CONTEXTO}

\section{0 texto grego}

O presente texto encontra-se na bíblia Novum Testamentum Graece: ${ }^{5}$

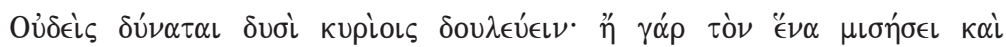

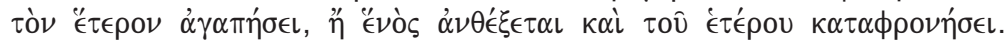

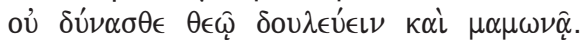

\section{Tradução}

A frase "Não podeis servir a Deus e ao dinheiro"7 encontra-se na perícope de Mateus 6,24, como podemos visualizar a seguir:

"Ninguém pode servir a dois senhores. Com efeito, ou odiará um e amará o outro, ou se apegará ao primeiro e desprezará o segundo. Não podeis servir a Deus e ao Dinheiro".

4 MONCINI, R. Existência e gratuidade. Antropologia da partilha. São Paulo: Paulus, 2000. pp. 183-189.

5 NESTLE-ALAND. Novum Testamentum Graece. 27 revidierte Auflage. Stuttgart: Deutsche Bibelgesellschaft, 1993.

6 DE OLIVEIRA, C. F. O serviço como essência (Mc 10,41-45). Revista de Cultura Teológica. São Paulo, Paulinas, XVII, 67, abr/jun 2009, p. 67: "A LXX utiliza pouquíssimo a palavra serviço. Com exceção de $\operatorname{Pr} 10,4$, onde a palavra parece indicar o trabalhador subordinado, distinguindo geralmente o servidor ou o vassalo da coorte ou do rei. Alguma vez a palavra traduzida por 'servir' vem de דתָז como é o caso de Dt 6,13: 'e somente o teu Deus servirás'. Ou do serviço manual ou escravo, de prestar um trabalho a alguém, que traduzem com a palavra

7 DE FRAINER, J. M. Dicionário enciclopédico da Bíblia. Organizador: A. Van Den Born. 2. ed.

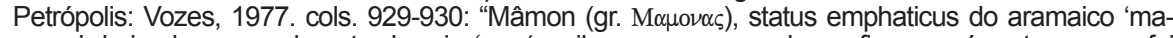
mona' derivado provavelmente da raiz ' $m n$ (aquilo em que se pode confiar, que é certo ou que foi

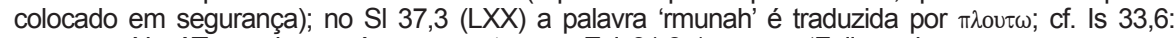

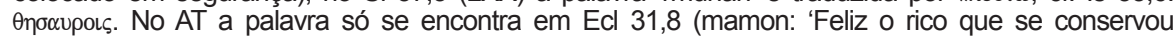
sem mancha, que não foi atrás do ouro e não pôs sua segurança no dinheiro e nos tesouros'), no apócrifos do AT é esporádica mas frequente nos Targuns e no Talmude. Significa posses, propriedade (não exclusivamente dinheiro) e tem também no judaísmo não poucas vezes um sentido pejorativo; conforme S. Agostinho (de Serm, Dni in monte 2,14,47; ML 34,1290), o termo púnico para lucro era Mâmon. No NT, Mâmon encontra-se em Mt 6,24 (=Lc 16,13 e Lc 16,9.11), sempre numa palavra do Senhor. Nos dois primeiros textos Jesus quase personifica o Mâmon, como um poder demoníaco, cujo escravo se torna o homem avaro, e cujo serviço é incompatível com o serviço de Deus. Em Lc 16,9.11 é usada duas vezes a expressão 'o Mâmon injusto', que é usada também em Hen 63,10 (aludindo ao Evangelho?) e nos Targuns, e pela qual é sugerido de que modo de fato as riquezas geralmente são adquiridas, aumentadas e empregadas. A existência de um deus sírio chamado Mâmon nunca foi provada". Conferir também ZERWICK. M.; GROSVENOR. M. A. Grammatical analysis of the Greek New Testament. 4. revised edition. Roma: Editrice Pontifício Istituto Bíblico, 1993. p. 17: mamwna/|: riqueza, dinheiro ou talvez personificação de Mammon. 


\section{Inserção e contexto}

Esta perícope foi inserida em um conjunto mais amplo que compreende os capítulos 5-7 do evangelho de Mateus. A inteira seção trata do bem conhecido discurso sobre o Sermão da Montanha. Nele, a construção concêntrica se evidencia, pois ao dispormos as sequências temáticas, segundo a Bíblia de Jerusalém, ${ }^{8}$ o centro é justamente o nosso versículo em questão:

$$
\begin{aligned}
& \text { 5,1-12 - As bem-aventuranças } \\
& 5,13-16-\text { O sal da terra e a luz do mundo } \\
& 5,17-19-\text { O cumprimento da lei } \\
& 5,20-48-\text { A nova justiça é superior à antiga } \\
& 6,1-4-\text { A esmola em segredo } \\
& 6,5-6-\text { A oração em segredo } \\
& 6,7-15-\text { A oração do discípulo } \\
& 6,16-18-\text { O jejum em segredo } \\
& 6,19-21-\text { O sentido da vida } \\
& 6,22-23-\mathrm{A} \text { orientação da vida } \\
& 6,24-\mathrm{A} \text { opção fundamental } \\
& 6,25-34-\mathrm{A} \text { busca fundamental } \\
& 7,1-5-\text { Só Deus pode julgar } \\
& 7,6-\mathrm{A} \text { responsabilidade da fé } \\
& 7,7-11-\text { Confiar do Pai } \\
& 7,12-\mathrm{A} \text { regra de ouro } \\
& 7,13-14-\text { Os dois modos de viver } \\
& 7,15-20-\text { Os falsos profetas } \\
& 7,21-23-\text { O discípulo autêntico } \\
& 7,24-27-0 \text { modo autêntico de viver } \\
& 7,28-29-\mathrm{A} \text { autoridade do mestre }
\end{aligned}
$$

Nesse tipo de construção, seu funcionamento é como na matemática, ${ }^{9}$ onde o número colocado antes do parêntese vale para todos os números dentro dele: embora não sejam repetidos cada vez, valem para cada palavra do Sermão da Montanha. Se tomarmos como exemplo o tema da opção fundamental com as premissas desse discurso que estão em Mateus, teremos

8 BíbliA de JeRUSALÉm (A). Novo Testamento. Tradução Portuguesa. São Paulo: Paulus, 1975. 9 JEREMIAS, J. O Sermão da Montanha. São Paulo: Paulus, 1984. p. 53: "Todo o Sermão da Montanha, como, na matemática, o número colocado diante do parêntese vale para todos os números dentro dele: embora não seja repetido cada vez, vale para cada palavra". 
a seguinte fórmula: 6,24(5,3-16). Assim sendo, podemos intuir que, fazendo a opção fundamental de servir ao único Senhor, que é Deus, haveremos de ser felizes (vv. 3-12) e modelo enaltecedor de discípulo (vv. 13-16), sal da terra e luz do mundo. A premissa contrária também é verdadeira: somos felizes e modelo de discípulo porque optamos por servir unicamente a Deus.

Outro exemplo, oportuno para este trabalho, é a aplicação da fórmula matemática acima citada ao capítulo 6 , tendo como elemento básico o nosso texto em questão: 6,24(6,1-4.5-15.16-18.19-23.25-34). Neste capítulo Mateus obedece a uma sequência lógica de conselhos evangélicos que os estudiosos afirmam serem conselhos para os catecúmenos de sua comunidade: a importância da esmola (vv. 1-4), da oração (vv. 5-15), do jejum (vv. 16-18), do sentido e da orientação da vida (vv. 19-23), o texto em questão (v. 24) e a importância da confiança na providência de Deus (vv. 25-34). Faz-se necessária, portanto, uma leitura do capítulo 6, o qual nos ajudará a compreender melhor o versículo 24 , evitando, assim, conclusões moralistas e idealistas do texto e de todo o capítulo.

\section{A questão da esmola 6,24 (6,1-4)}

O texto 6,1-4 nos chama a atenção para os cuidados na prática da justiça. Para Mateus, a prática da justiça é sinônima da prática divina, pois somente Deus é justo. No próprio episódio do batismo de Jesus, temos a afirmação: "Jesus, porém, respondeu-lhe: Por ora, deixa, é assim que devemos cumprir toda a justiça! E João deixou" (Mt 3,15).

Assim, dar esmola não deve ser ocasião de promoção pessoal, mas de revelar Deus. Qualquer atitude que envolva um movimento econômico deve ser sempre a ocasião para glorificar a Deus. Não são coisas que Deus quer, mas um projeto de vida com os irmãos, isto é, um projeto de não ter dois mestres e não ser dividido por dentro $(6,24)$.

\section{A questão da oração 6,24 (6,5-15)}

O texto 6,5-15 nos ajuda a compreender que não se deve esperar de Deus nada além do essencial para a vida, isto é, o pão de cada dia. Todo o restante depende da nossa opção fundamental $(6,24)$, que consiste em santificarmos o nome de Deus construindo o seu Reino e realizando a sua vontade. Isto consiste em perdoarmos os nossos devedores, evitando, assim, servir ao Maligno. É isso que devemos pedir a Deus. 
Não podeis servir a Deus e ao dinheiro! (Mt 6,24)

A questão do jejum 6,24 (6,16-18)

O jejum é um caminho natural que nos ajuda a perceber a nossa dependência diante dos outros $(6,16-18)$. Ter dinheiro ou praticar a oração não garante a ninguém ser o todo-poderoso, pois somos dependentes de um conjunto de coisas para nos mantermos vivos. Jejuar nos ajuda a optar $(6,24)$ e a descobrir a importância de Deus e da sua criação: descobrimos a importância da terra, da lavoura, dos animais; descobrimos também a importância do outro: do lavrador, do distribuidor. Sem eles não temos como alimentar-nos a contento, pois não temos condições de produzir, sozinhos, tudo aquilo de que necessitamos.

\section{O sentido e orientação da vida 6,24 (6,19-23)}

Jesus propõe como referência dois tipos de tesouros possíveis de serem ajuntados: o tesouro ajuntado na terra, ou o tesouro ajuntado no céu $(6,19-23)$. Nisto quem nos ajuda é São Paulo, o qual já havia nos alertado para a necessidade de uma opção fundamental $(6,24)$, aquela de sermos cidadãos do alto, evitando assim a tentação da carne, isto é, evitando os valores cultivados pelos não cristãos (Rm 8,1-13). Para os cristãos, a prática do dia a dia deve ser pautada pelos valores recomendados por Deus, e isto implica também ajuntar os tesouros do alto. Como ser cidadãos do alto? Não há outra saída a não ser tornando-se imagem e semelhança de Deus (Gn 1,27). Mas como podemos ser sua imagem e sua semelhança? Dando a nossa colaboração para a obra da criação, e isso é possível por meio do trabalho. É a partir do trabalho que podemos exercer a capacidade de criar e recriar as coisas. É por meio do trabalho que podemos revelar a imagem de Deus e a de sermos luz (Jo 9,4-5). É no trabalho, portanto, que vamos encontrar as bases de uma economia capaz de glorificar e de revelar Deus.

\section{A busca fundamental 6,24 (6,25-34)}

A nossa opção fundamental chega ao mais profundo da existência humana, isto é, a busca pela sobrevivência: comer, beber e vestir (6,25-34). De fato, se vivemos divididos em servir a dois senhores $(6,24)$, tal busca tornar-se-á um grande mal, mesmo tendo a consciência de ser a vida mais que o alimento que, na cadeia econômica da criação humana, é conquistado por meio do trabalho. ${ }^{10}$

10 ANDERSON, A. F.; GORGULHO, G. Os sábios na luta do povo. São Paulo: Centro Ecumênico de Publicações e Estudos Frei Tito de Alentar Lima (Praça da Sé, n. 158, 7ํo andar), 
Dentro de uma visão estreita e limitada pela divisão entre dois senhores, somos incapazes de ver essa criação humana como um elemento pulsante que nos conecta para a totalidade de nossa história, que nos transcende ao próprio Criador e dá sentido à nossa existência. $O$ alimento é fruto do trabalho do homem que trabalha a terra, transforma e domina. Logo, trabalho é técnica, é tecnologia, é aquilo que avança e nos dá vida digna para retornar, cem por um, ao seu Criador, nosso Deus. Portanto, ter dignidade é mais que comer, é mais que beber, é buscar em primeiro lugar o Reino e sua Justiça.

\section{DO TEXTO À REALIDADE}

O nosso texto em questão, Mt 6,24, inserido no discurso da montanha, pertence ao gênero literário didaqué, ${ }^{11}$ cuja finalidade era instruir a comunidade primitiva. A situação histórica ou o sitz im Leben desse gênero literário remonta a dois grupos liderados pelos escribas e fariseus, conforme Mt 5,20: "Com efeito, eu vos asseguro que, se a vossa justiça não exceder a dos escribas e fariseus, não entrarão no Reino dos Céus". O primeiro grupo tratava-se de teólogos formados e o segundo de leigos piedosos no ramo do comércio, operariado e artesanato. ${ }^{12}$ Ora, ao dirigir um discurso para esse tipo de pessoa, cujo conteúdo era o de não servir a Deus e ao dinheiro, certamente não se quer contestar a riqueza em si mesma, mas contestar os pilares que sustentam uma sociedade, a saber: a riqueza, o poder e a religião. Tais pilares remontam à sociedade do tempo de Jesus, onde o Templo repousava nesses três fundamentos.

Segundo Houtart, "o Templo representava um 'centro de trabalho que, juntamente com os príncipes das famílias herodianas, criou um proletariado artesanal que era o mais bem remunerado da Palestina, com uma tradição familiar e um prestígio social que o distinguiria não só do proletariado agrícola, como da massa de artesãos por conta própria'. Não seria exagerado dizer que o Templo era o mais poderoso aparelho estatal, exercendo uma função de centralização do poder e dominação exercidos sobre o povo". ${ }^{13}$ Certamente, essa economia tornava o trabalho um meio incompatível com o serviço de Deus.

1991. p. 91: "O trabalho pode ser a raiz da alienação, como é a raiz de realização humana na sociedade (Qo 1,2-3)".

11 JEREMIAS, O Sermão da Montanha, pp. 33-37.

12 JEREMIAS, O Sermão da Montanha, pp. 38-39.

13 HOUTART, F. Religião e modos de produção pré-capitalista. São Paulo: Paulus, 1982. pp. 207-208. 
Jesus diz, no início do Sermão da Montanha, em Mt 5,4: "Felizes os mansos, porque herdarão a terra". Aqui a terra de herança ${ }^{14}$ é um dom conquistado por meio do trabalho ${ }^{15}$, diferente do modelo econômico do Império Romano, onde a terra era propriedade do rei, conquistada pelo acúmulo de dinheiro e riquezas. O sistema do "dom" aponta para um novo modelo econômico e para uma nova maneira de conceber a sociedade e sua organização a partir da graça que é partilhar e participar. Em Mt 4,1-11, o diabo propõe uma realeza que teria como base a sustentação do sistema de pureza ritual. Jesus rejeita essa proposta citando o livro de Dt 8,3.10-18: "Não só de pão vive o homem". Aqui também está presente o sistema do "dom". Por isso, o Deuteronômio abre caminho e prepara Jesus de Nazaré, que procura reavivar o sistema do "dom" e vai contra a concentração dos bens (terra de herança) na mão de poucos, desencadeando, assim, relações de poderes econômicos e sociais injustos, onde qualquer um que se manifeste contra é injuriado e perseguido.

\section{SERVIR A DEUS E/OU AO DINHEIRO?}

No AT há uma vasta literatura que contribuiu para a formação da tradição sobre a questão do dinheiro ou das riquezas e que está na base da formação de nossa perícope em estudo. O Eclesiastes é um dos livros do AT que nos fornece uma conexão com a grandeza dinheiro ou riquezas por meio da palavra $\mu \alpha \mu \omega \nu \alpha$. Sua tradução vem do aramaico pִ̣̦ (divitiae $)^{16} \mathrm{e}$ derivada, provavelmente, da raiz hebraica המוץ (divitiae), ${ }^{17}$ tal como encontrada em Ecl 5,9: "Quem ama o dinheiro nunca está farto de dinheiro, quem ama a abundância nunca tem vantagem. Isso também é vaidade".

14 NELIS, J. T. Dicionário enciclopédico da Bíblia. Organizador: A. Van Den Born. 2. ed. Petrópolis: Vozes, 1977. col. 1.494: "Javé jurou dar a Israel a terra como herança (Lev 20,24; Dt 7,13.15; 1Rs 8,34.40), mas a posse da terra é condicionada pela observância da Lei de Deus; só se Israel obedecer às suas prescrições, Ele abençoará os frutos de sua terra (trigo, mosto, óleo) (Dt 7,13) e Ihe dará uma vida longa nesta terra (Ex 20,2; Dt 4,10; 5,16 etc.). Como o Sinai (Ex 3,1) assim também a Palestina é terra sagrada (Zac 2,16), por ser a terra de Javé (Is 14,2; 1Crôn 7,20)".

15 BORN, A. Van Den. Herança. In: Dicionário enciclopédico da Bíblia. Organizador: A. Van Den Born. 2. ed. Petrópolis: Vozes, 1977. col. 684: "A palavra hebraica para herdar (nahal) tem sentido mais largo do que herdar no português, pois não exprime apenas o tomar posse em razão de herança, como também na base de qualquer outro título que não seja o próprio trabalho".

16 Cf. ZOREL, F. Lexicon Hebraicum veteris testamenti. Fasc. 1-9. Romae: Pontificium Institutum Biblicum, 1984. p. 444.

17 Cf. ZOREL, Lexicon Hebraicum veteris testamenti, p. 194. 
O que significa a vaidade? Conforme o livro do Eclesiastes, a vaidade consiste na felicidade momentânea, no acumular bens ( $\mathrm{Ecl} 4,7-8)$, no amor ao dinheiro e às riquezas ( $\mathrm{Ecl} 5,9-10$ ), na busca de sermos eternos ( $\mathrm{Ecl}$ $9,11-12$ ) e no trabalho que realizamos com esforço e suor para que os outros que em nada colaboraram desfrutem $(\mathrm{Ecl} 2 ; 6,2) .{ }^{18}$

O livro do Eclesiastes nos oferece uma reflexão sobre o trabalho. A economia é a base do trabalho; então, esse livro pode nos oferecer critérios de reflexão sobre a economia. ${ }^{19}$ De fato, logo no seu início o livro do Eclesiastes nos fala da vaidade (Ecl 1,2). O livro do Eclesiastes indica uma tensão existente entre o trabalho e o desfrute dele. $O$ profeta Isaías (Is 65,21-23) e outros livros da Bíblia vão acompanhar a mesma reflexão. Quando o trabalho de um é destinado para o desfrute de outro isso é vaidade. Quando o trabalho de um, ainda que com suor e fadiga, destina-se ao desfrute de quem trabalhou, isso é dom de Deus (Ecl 3,13; 5,17-19; 9,7-9). A vaidade e o dom de Deus são antagônicos. Assim sendo, quando a economia é o resultado do esforço do próprio trabalho, isso é dom de Deus, um tesouro ajuntado no céu. Mas, quando a economia obtém resultado, fruto da especulação e da exploração do trabalhador, isso é vaidade; ajunta-se um tesouro na terra. ${ }^{20}$

Agora, já temos elementos suficientes para compreender quais são os dois senhores a que o texto de Mt, 6,24 se refere: uma economia resultante do trabalho ou uma economia resultante da especulação e alienação. A economia que resulta do trabalho serve para sermos a imagem de Deus,

18 ANDERSON; GORGULHO, Os sábios na luta do povo, pp. 90-91: "A 'alienação tem sua raiz no valor do trabalho': o 'proveito' do trabalho não volta e nem realiza o sujeito que é o trabalhador' (Qo 1,2-3)".

19 ANDERSON; GORGULHO, Os sábios na luta do povo, pp. 89-90: "Queremos mostrar que o Eclesiastes é uma reflexão sobre o impacto do regime escravagista, dos Ptolomeus do Egito, sobre a economia e vida dos judeus na Palestina. Nesta situação, o nosso Sábio procura refletir sobre o valor do trabalho e sua repercussão na 'porção' humana. O valor do trabalho coloca o problema da relação entre pessoa e sociedade. A tese de Qohelet é a busca do valor do trabalho para entender o que é a 'porção' humana que se vive no tempo (Qo 1,2-3; 9,9-10)".

20 ANDERSON; GORGULHO, Os sábios na luta do povo, pp. 104-105: "A última parte sobre a crítica social está em Qo 5,7-6,9. O autor mostra a força destruidora do fetiche: Ela está no dinheiro. Este se torna um falso 'valor' que destrói e impede a realização do verdadeiro 'valor' do trabalho humano [...]. A crítica do 'dinheiro' mostra como o fetiche se torna uma força impessoal e corroedora das relações sociais. O discernimento deve ir ao 'valor' do dinheiro que não é garantia para a vida e para a realização do 'valor do trabalho'”. 
pois realizamos a sua vontade e seguimos os seus conselhos, isto é, servir a Deus. Uma economia que resulta da especulação e alienação não permite revelar a imagem de Deus, pois não tem como meta o trabalho, mas a exploração e a alienação das pessoas. Certamente, esta economia estará servindo ao dinheiro.

Qual é o tipo de julgamento que podemos fazer quanto à economia que estamos servindo hoje? Nenhum modelo econômico satisfaz plenamente a vontade de Deus, pois todos os modelos econômicos estão limitados pelas contingências da própria história. Entretanto, Deus não depende de nenhuma economia (Is 55,1-2), Deus não depende da história e das suas contingências, Ele é eterno (Is 44,6; SI 93,2). Assim sendo, somos convidados a contemplar Jesus, pois, embora sendo Deus, ele se submeteu às contingências históricas (FI 2,6-11).

\section{A ECONOMIA QUE GERA VIDA}

Jesus, na passagem conhecida como "a multiplicação dos pães", chama a nossa atenção para este fato (Mc 6,30-44). Ali, Ele nos ensinou a necessidade de sempre superarmos a economia vigente. Neste texto, dois verbos estão em conflito: o verbo "dar" e o verbo "comprar". Jesus sugere aos apóstolos: Dai-lhes vós mesmos de comer, enquanto os discípulos respondem com uma pergunta: Iremos e compraremos duzentos denários de pão para dar-Ihes de comer? (Mc 6,37). Este conflito aparece na

incompreensão dos discípulos, que nasce do desafio à fé que eles têm: devem dar de comer ao povo. Antes, porém, faz-se necessário renunciar aos esquemas dominantes de resolver o problema arraigado no "comprar" pela lógica do Reino, isto é, "compartilhar". Por outro lado, o comprar e o compartilhar não são meras atitudes isoladas, mas revelam modelos sociais diferentes ou, mais especificamente, diferentes modos de produção. ${ }^{21}$

O verbo "dar" é uma prática constante de Deus: "É Ele quem dá a cada um sua alimentação, colocando o homem no mundo para saciar-se.

21 TEIXEIRA, C. Eucaristia: uma comensalidade conflitiva. Revista de cultura teológica. São Paulo-SP: Vozes, 30, 2000, pp. 23-24: cf. Também a nota 18 no mesmo artigo. 
Desde as origens Deus vela sobre sua obra. Mesmo decaído, o homem é colocado em responsabilidade pelo Criador, que toma cuidado com aqueles aos quais ele dá vida e os coloca em sua própria mesa, possibilitando uma identidade e comunhão de vida". ${ }^{22}$

O verbo "comprar", por sua vez, é oriundo da organização humana, da econômica. Na sociedade do tempo de Jesus,

o dinamismo compra e venda era estabelecido pelo dinheiro. Este, por sua vez, estava concentrado em torno dos possuidores de riquezas e principalmente do Estado e do Templo, que, juntos, exerciam o papel de grandes centros de poder e dominação econômica. $O$ fruto do trabalho do homem estava presente em todos os setores da sociedade: de um lado penetrava na aldeia, na casa e na mesa, e por outro lado, na cidade, no Templo e no comércio. A exploração campo/cidade, gerada pelo comércio, levava a sociedade no tempo de Jesus a uma inversão de valores colocando o dinheiro e seu sistema monetário acima da pessoa humana. Uma economia baseada nestes princípios não expressava mais a vida dos trabalhadores, seu sangue, sua inteligência, seu esforço, seu amor, sua alegria, sua felicidade e nem mesmo a possibilidade de suprir as necessidades dos diversos setores produtivos. Torna-se uma verdadeira dominação econômica, porque do produto do trabalho é tirado muito dinheiro. Consequentemente, a enorme distância existente entre a classe rica e a humilde e o porte reduzido da classe média faziam com que não existisse para os pobres esperança de promoção humana, nem tivessem meios para mudar sua situação, dependendo sempre da vontade dos poderosos. ${ }^{23}$

Jesus supera a economia, não para que tenhamos de viver, enquanto cristãos, em uma "bolha"; mas o sinal por ele realizado quer nos inspirar a procuramos sempre soluções e alternativas para as necessidades do povo como primazia às necessidades especulativas da economia vigente. Jesus prioriza a vida do povo em detrimento da especulação econômica,

22 TEIXEIRA, C. A importância da mesa de refeição no anúncio da traição Mc 14,17-21. Dissertatio ad Lauream in facultate S. Theologiae Apud Pontificiam Universitatem S. Thomae in Urbe. Romae: s.n., 1998. p. 173.

23 TEIXEIRA, A importância da mesa de refeição no anúncio da traição Mc 14,17-21, pp. 160-162. 
ajudando-nos a compreender que não se pode acomodar em um modelo econômico, mas sim estarmos constantemente preocupados em superá-lo, aprimorá-lo, a fim de que ninguém esteja excluído de suas necessidades básicas. ${ }^{24}$ Dessa forma, Jesus faz cumprir a vontade de Deus revelada nas Escrituras (Lv 19,11-15; Dt 24,6.10-15; Jr 22,13; MI 3,5; Tg 5,4).

O exemplo apresentado por Jesus é um convite para pensarmos em estratégias que possam superar a realidade pecaminosa do modelo econômico atual que exclui uma imensa porção dos filhos de Deus como foi denunciado na Conferência de Aparecida. ${ }^{25}$

\section{CONCLUSÃO}

Basicamente, três questionamentos brotam da reflexão acima: (a) é possível uma sociedade baseada em uma economia pautada pela gratuidade? (b) Existe harmonia entre Deus e o dinheiro? (c) O que dizer do Reino de Deus diante da nossa realidade?

Diante do exposto acima, podemos afirmar com segurança: qualquer economia que não parta da gratuidade ${ }^{26}$ não pode ser considerada uma

24 TEIXEIRA, A importância da mesa de refeição no anúncio da traição $M c$ 14,17-21, pp. 192 : "É de dentro da sociedade no tempo de Jesus que surge um movimento novo, de homens que um dia fizeram parte de instituições, renunciaram a tudo para seguir os ensinamentos do Mestre. Apesar dos velhos vícios impregnados, como do poder, do ter, do comprar, aprendem a servir, a dar e a partilhar. O centro desta prática era o momento de refeição, pois resume todo o fundamento da prática de Jesus, do antigo sistema social de Israel e a antecipação da esperança de viver em sintonia com o Deus da vida".

25 DOCUMENTO DE APARECIDA. Texto Conclusivo da V Conferência Geral do Episcopado Latino-Americano e do Caribe. 3. ed. São Paulo: Paulus, 2007. pp. 37-43: "O Papa, em seu Discurso Inaugural, vê a globalização como um fenômeno 'de relações de nível planetário', considerando-o 'uma conquista da família humana' porque favorece o acesso a novas tecnologias, mercados e finanças [...]. Lamentavelmente, a face mais difundida e de êxito da globalização é sua dimensão econômica, que se sobrepõe e condiciona as outras dimensões da vida humana [...]. Conduzida por uma tendência que privilegia o lucro e estimula a concorrência, a globalização segue uma dinâmica de concentração de poder e de riqueza em mãos de poucos [...]. Por isso, diante dessa forma de globalização, sentimos forte chamado para promover uma globalização diferente, que esteja marcada pela solidariedade, pela justiça e pelo respeito aos direitos humanos, fazendo da América Latina e do Caribe não só o continente da esperança, mas também o Continente do amor [...]. Isto nos deveria levar a contemplar os rostos daqueles que sofrem [...]. A exploração do trabalho chega, em alguns casos, a gerar condições de verdadeira escravidão".

26 Cf. BENTO XVI, Caritas in Veritate, p. 8. § 5. 
economia cristã e não atingirá a paz e a justiça, ${ }^{27}$ uma vez que gratuitamente Deus nos concede a vida. Está aí um grande programa para a evangelização dos economistas que cada geração de cristãos deverá assumir como um compromisso missionário de anunciar o Reino.

A harmonia entre Deus e o dinheiro não se obtém por meio de um debate acadêmico fechado na precisão de conceitos, pois Deus é uma realidade aberta e eterna, enquanto o dinheiro é uma realidade factual, pontuada por programas econômicos limitados pela história. Assim sendo, qualquer proposta que procure harmonizar Deus e o dinheiro terá que ser orientada pelo próprio Deus vivo e verdadeiro que, em Mateus e na pessoa de Jesus, se apresenta como o Mestre de Justiça. Se o dinheiro colaborar para a justiça e para a vida em abundância da humanidade, não haverá conflito. Se o dinheiro for utilizado para a exploração do irmão, não haverá harmonia. A economia deve ser reconhecida e vivida num contexto que solicita ao ator humano um "deixar", um claro "desprendimento interior", uma opção fundamental: ou Deus ou o Dinheiro. ${ }^{28}$

Quanto ao Reino de Deus diante de nossa realidade, não é difícil detectar que existem alguns sinais do Reino de Deus entre nós, aqueles apontados como: economia solidária, economia de comunhão e cooperativas econômicas. Há também pronunciamentos proféticos sobre economia como a dos bispos americanos, que escreveram uma carta pastoral sobre a economia em 1986, intitulada Justiça econômica para todos: "As instituições sociais devem ser construídas de forma a garantir que os indivíduos tenham acesso aos bens materiais mínimos e tenham asseguradas as relações interpessoais e as liberdades fundamentais, que são indispensáveis para a sua participação na vida social. Quando a economia nega os direitos básicos que nutrem e protegem a dignidade humana que prejudica o indivíduo, ela fere também a comunidade como um todo". ${ }^{29}$

Contudo, estamos ainda bastante distante do ideal anunciado por Jesus no evangelho de Lucas (LC 4,14-19).

27 Cf. BENTO XVI, Caritas in Veritate, p. 5. § 1.

28 Cf. COSTA, R.; ARAÚJO, V.; BIELA, A.; SORGI, T.; FERRUCCI, A.; GUI, B. Economia de comunhão; projeto, reflexões e propostas para uma cultura da partilha. 2. ed. São Paulo: Cidade Nova, 1998. p. 44.

29 TONETI, E. D. Justiça econômica para todos: doutrina social da Igreja e a economia americana. Revista eletrônica: www.teologia-assuncao.br. número III, ano II 2008. 


\section{REFERÊNCIAS BIBLIOGRÁFICAS}

ANDERSON, A. F.; GORGULHO, G. Os sábios na luta do povo. São Paulo: Centro Ecumênico de Publicações e Estudos Frei Tito de Alencar Lima, 1991. BENTO XVI. Caritas in Veritate. Brasília: CNBB, 2009.

BÍBLIA DE JERUSALÉM (A). Novo Testamento. Tradução Portuguesa. São Paulo: Paulus, 1975.

BORN, A. Van Den (org.). Herança. Dicionário enciclopédico da Bíblia. 2. ed. Petrópolis: Vozes, 1977.

CONIC - CONSELHO NACIONAL DE IGREJAS CRISTÃS DO BRASIL. Campanha da Fraternidade Ecumênica 2010. Economia e Vida. Texto-Base. CNBB, 2009.

COSTA, R.; ARAÚJO, V.; BIELA, A.; SORGI, T.; FERRUCCI, A.; GUI, B. Economia de comunhão; projeto, reflexões e propostas para uma cultura da partilha. 2. ed. São Paulo: Cidade Nova, 1998.

DE FRAINER, J. Mâmon. Dicionário enciclopédico da Bíblia. Organizador: A. Van Den Born. 2. ed. Petrópolis: Vozes, 1977.

DE OLIVEIRA, C. F. O serviço como essência (Mc 10,41-45). Revista de Cultura Teológica, São Paulo, ano XVII, n. 67 (abr/jun 2009).

DOCUMENTO DE APARECIDA. Texto conclusivo da $V$ Conferência Geral do Episcopado Latino-Americano e do Caribe. 3. ed. São Paulo: Paulus, 2007.

HOUTART, F. Religião e modos de produção pré-capitalista. São Paulo: Paulinas, 1982.

JEREMIAS, J. O Sermão da Montanha. São Paulo: Paulus, 1984.

MONCINI, R. Existência e gratuidade; antropologia da partilha. São Paulo: Paulus, 2000.

NELIS, J. T. Dicionário enciclopédico da Bíblia. Organizador: A. Van Den Born. 2. ed. Petrópolis: Vozes, 1977.

NESTLE-ALAND. Novum Testamentum Graece. 27 revidierte Auflage. Stuttgart: Deutsche Bibelgesellschaft, 1993.

TEIXEIRA, C. Eucaristia: uma comensalidade conflitiva. Revista de Cultura Teológica. São Paulo, n. 30, 2000.

TEIXEIRA, C. A importância da mesa de refeição no anúncio da traição Mc 14,17-21. Dissertatio ad Lauream in facultate S. Theologiae Apud Pontificiam Universitatem S. Thomae in Urbe. Romae: s.n., 1998.

TONETI, E. D. Justiça econômica para todos: doutrina social da Igreja e a economia americana. Revista Eletrônica. www.teologia-assuncao.br., n. III, ano II, 2008.

ZOREL, F. Lexicon Hebraicum veteris testamenti. Fasc. 1-9. Romae: Pontificium Institutum Biblicum, 1984. 